\title{
Relationships between spatial patterns of benthic assemblages in a mangrove forest using different levels of taxonomic resolution
}

\author{
M. G. Chapman* \\ Centre for Research on Ecological Impacts of Coastal Cities, Marine Ecology Laboratories A11, \\ University of Sydney, New South Wales 2006, Australia
}

\begin{abstract}
The use of multivariate techniques to quantify spatial and temporal patterns in assemblages requires decisions about the resolution to which taxa are identified. Similar spatial patterns in assemblages are often found whether coarse or fine levels of taxonomic resolution are used. Whether coarser resolution retains patterns of relative difference in assemblages between habitats at a hierarchy of spatial scales has not been widely examined. Where organisms are patchy at many spatial scales, numerous replicates are needed to represent assemblages adequately. Identifying taxa into broad groups is generally quicker and cheaper than identification to species, so coarser resolution may release limited resources for the intensive sampling necessary for populations of highly dispersed and patchy organisms. In this study, intertidal epifaunal assemblages in urban mangrove forests were examined at scales of metres, tens of metres and hundreds of metres using 2 different levels of taxonomic resolution: 93 taxa and 9 broad groups. Bray-Curtis measures of dissimilarity were also compared between the 2 levels of taxonomic resolution to test the hypothesis that quantitative differences in the assemblages at a hierarchy of spatial scales were retained with different levels of taxonomic resolution. Assemblages varied at each spatial scale. Similar patterns were obtained at each level of taxonomic resolution because the Bray-Curtis measures of dissimilarity were strongly correlated between the 2 levils. More variable sites, as identified using one level of taxonomic resolution, were also more variable using a different level of taxonomic resolution. Also, sites that were similar to each other when 93 taxa were used remained similar when the taxa were grouped into 9 groups. Transforming the data to the fourth root retained patterns of differences between sites, but altered patterns of variability within sites. The relative value of putting limited resources into increasing the size of the sample as opposed to increased taxonomic resolution in such habitats is discussed.
\end{abstract}

KEY WORDS: Spatial pattern - Variance Multivariate analyses - Benthos Mangrove

\section{INTRODUCTION}

Differences in assemblages of organisms between potentially impacted and control locations are frequently examined using non-metric, multidimensional scaling (nMDS) and analysis of similarities (ANOSIM) on Bray-Curtis measures (Clarke \& Green 1988, Gray et al. 1988, Warwick et al. 1990, Clarke 1993, Chap-

•E-mail: gee@bio.usyd.edu.au man et al. 1995). These techniques have also been used to identify natural disturbances, such as those due to burrowing crabs (Warwick et al. 1990), to quantify patterns of diversity among habitats (Oliver \& Beattie 1996, Underwood \& Chapman 1998) and to illustrate large-scale biogeographical patterns (Bustamante \& Branch 1996). These analytical procedures require decisions about the resolution to which taxa are identified. Taxonomic resolution is often determined phylogenetically, for example, fauna are identified to species, genera, families, etc. (Gray et al. 1988, 
1990, Warwick 1988). There has been recent interest in the use of ecological attributes, such as trophic level rather than phylogenetic relationships, to group species (Somerfield \& Clarke 1995). Generally, coarser levels of taxonomic resolution show similar patterns of differences among assemblages as do finer levels of resolution.

There are many reasons why grouping species might be advantageous. Identifying taxa to species is timeconsuming and therefore expensive. In Australia and probably most countries, it is not possible to identify all taxa to species because the taxonomy of many groups is not known. Therefore, taxonomic resolution will generally vary among phyla, with the more wellknown groups (e.g. molluscs and crustaceans) identified to a finer taxonomic level than the less well-known groups (such as nematodes or nemerteans) (e.g. Grall \& Glémarec 1997). It is quicker and more accurate to train personnel to sort samples into morphospecies (Oliver \& Beattie 1996) or other broad groups than to train them to identify specimens to species. Because less time is needed to sort samples, reduced costs may of fset the cost of the large number of replicates needed to quantify the patterns of abundances adequately.

Large numbers of studies in many habitats have shown that assemblages of invertebrates vary, often interactively, at many different spatial and temporal scales (e.g. Morrisey et al. 1992, 1993, Thrush et al. 1994, Underwood \& Chapman 1996). Therefore, to quantify and accurately describe spatial patterns and temporal trends in such variable habitats, hierarchical sampling designs are needed (Underwood 1997). This is especially important when attempting to measure potential environmental impacts in such variable populations (Underwood 1994). Most ecological studies necessitate complex, hierarchical sampling designs which, in turn, generally demand relatively large numbers of replicates.

Most studies on marine assemblages that have evaluated different levels of taxonomic resolution to quantify spatial patterns have been subtidal. There are few similar studies in intertidal habitats. It is important that the applicability of taxonomic grouping be tested in different habitats before it is accepted as a general procedure. Other studies have also usually compared different levels of taxonomic resolution at a single spatial scale (e.g. between control and experimental treatments; e.g. Gray et al. 1988). Changes in assemblages at the level of species, genera, families, etc., are, however, likely to vary according to the scale of sampling, i.e. the distance between samples.

Finally, many previous studies have shown that overall patterns of differences among sets of replicates are maintained with different taxonomic resolution, i.e. control sites continue to group separately from treated sites in nMDS plots using different taxonomic resolution. These procedures do not examine whether all differences among samples are retained, e.g. whether relative differences between pairs of samples are retained, although the RELATE procedure in the PRIMER package is designed to test for correlations between all pair-wise comparisons in 2 similarity matrices. This procedure does not, however, specifically examine correlations between these patterns at a hierarchy of scales, which is necessary for understanding how well different levels of taxonomic resolution characterize spatial patterns.

In this study, intertidal epifaunal assemblages in an urban mangrove forest in Sydney Harbour (New South Wales, Australia) were examined at a number of spatial scales using 2 different levels of taxonomic resolution. Locations hundreds of metres apart representing different habitats were likely to contain different assemblages. Replicate sites within each location (tens of metres apart) may or may not contain similar assemblages. Replicate quadrats within each site (metres apart) are likely to contain similar assemblages. The first hypothesis tested was that the 2 levels of resolution would show similar patterns in the assemblages at each spatial scale.

The second hypothesis tested was that quantitative differences in the assemblages within and among sites would be similar at each level of taxonomic resolution. This was done by direct comparison of Bray-Curtis measures of dissimilarity at a hierarchy of spatial scales.

The average Bray-Curtis measure of dissimilarity within each site was calculated as the mean of all pairwise dissimilarities between replicates in that site. This gives a quantitative measure of variability among replicate quadrats, i.e. variability in the assemblage at the scale of metres. The hypothesis predicted that, if these values were calculated separately using each level of taxonomic resolution, there would be a positive correlation between the values from each site, i.e. sites which were less variable using one level of taxonomic resolution would also be less variable using the other level of taxonomic resolution. Similar tests were done to examine differences in assemblages at scales of sites (tens of metres) and locations (hundreds of metres). This is similar to procedures (RELATE) used by Somerfield \& Clarke (1995), although they compared entire similarity matrices from all replicates in rank scale. This present study compared quantitative (rather than relative or ranked) average differences in the assemblages among samples at a chosen hierarchy of spatial scales (rather than among all pairs of replicates).

Finally, this paper qualitatively evaluates the relative value of putting resources into collecting more samples or into better levels of taxonomic resolution. 


\section{MATERIALS AND METHODS}

Sampling methods. Recent studies of mangroves in urbanized, industrialized and relatively undeveloped parts of Port Jackson (New South Wales, Australia) quantified spatial and temporal patterns of benthic macro-invertebrates at scales of metres to tens of kilometres and months to years (Chapman \& Underwood unpubl. reports). Populations of all taxa were patchy, necessitating sampling at a hierarchy of spatial scales and the need for many samples to represent the assemblages. As part of this study, 4 patches of mangrove forest (locations), hundreds of metres apart, were selected to represent different conditions of tidal flushing. Locations 1 and 2 were isolated from tidal flushing, but, because of poor drainage, contained standing water after rain. Location 3 was isolated from tidal flushing, but was well drained. Location 4 was inundated by the tide each day. These locations were chosen to test hypotheses about effects of tidal flushing on the fauna, but the details are irrelevant to the focus of this paper. Here, they are used to represent 4 locations with different environmental conditions. In each location, two $12 \mathrm{~m}^{2}$ sites, approximately $40 \mathrm{~m}$ apart, were each sampled using 4 randomly placed $0.1 \mathrm{~m}^{2}$ quadrats in March and June 1995.

In each quadrat, the leaf litter and sediment were collected down to approximately $20 \mathrm{~mm}$ depth. This material was sieved through a $1 \mathrm{~mm}$ and a $500 \mu \mathrm{m}$ mesh sieve. The 2 components were preserved in $7 \%$ formalin solution and sorted under magnification. Generally, the coarse component was completely examined, but when there was a large amount, it was subsampled $(30 \%$ by wet weight). A pilot study showed that this gave reliable estimates of numbers of each taxon in the entire sample. Fauna were sorted from the fine material using several randomly chosen subsamples until approximately $30 \%$ by volume of the sample was sorted. All invertebrates were counted, identified and then stored in $70 \%$ alcohol. The numbers of each taxon were adjusted relative to the amount of material sorted to give estimates per quadrat.

Taxonomic resolution. At the tinest taxonomic resolution, the fauna were identified to 93 taxa (Table 1). Each group was identified to the finest level possible within the costs of the project, varying from species (or 'morphospecies'; Oliver \& Beattie 1996) to families, orders or phyla, depending on their relative abundances and available taxonomic expertise. Gastropods, bivalves, amphipods and isopods, which were widespread and numerically important, were identified to species or morphospecies. Polychaetes were identified to family. Insect larvae were numerous, but taxonomic expertise was not available to identify these to species, so they were identified to morphospecies or

Table 1. Levels of taxonomic resolution used for the different taxa in this study

\begin{tabular}{|c|c|c|c|c|}
\hline Major Group & Phylum & Class & Order & Finest taxonomic resolution \\
\hline Group A & Mollusca & Gastropoda & & 14 species \\
\hline Group B & Mollusca & Bivalvia & & 8 species; 1 family \\
\hline Group C & Annelida & Polychaeta & & 9 families \\
\hline Group D & $\begin{array}{l}\text { Annelida } \\
\text { Nematoda } \\
\text { Nemertea }\end{array}$ & Oligochaeta & & $\begin{array}{l}\text { Not identified further } \\
\text { Not identified further } \\
\text { Not identified further }\end{array}$ \\
\hline Group E & Crustacea & Malacostraca & Amphipoda & 6 species; 1 family \\
\hline Group F & Crustacea & Malacostraca & Isopoda & 7 species; 1 family \\
\hline Group G & Crustacea & $\begin{array}{l}\text { Malacostraca } \\
\text { Ostracoda } \\
\text { Maxillopoda }\end{array}$ & $\begin{array}{l}\text { Leptostraca } \\
\text { Cumacea } \\
\text { Tanaidacea }\end{array}$ & $\begin{array}{l}\text { Not identified further } \\
\text { Not identified further } \\
\text { Not identified further } \\
\text { Not identified further } \\
\text { Not identified further }\end{array}$ \\
\hline Group H & $\begin{array}{l}\text { Chaetognatha } \\
\text { Cnidaria } \\
\text { Sipuncula } \\
\text { Echiura } \\
\text { Arthropoda }\end{array}$ & $\begin{array}{l}\text { Anthozoa } \\
\text { Chelicerata }\end{array}$ & Acari & $\begin{array}{l}\text { Not identified further } \\
1 \text { species } \\
\text { Not identified further } \\
\text { Not identified further } \\
4 \text { morphospecies }\end{array}$ \\
\hline Group I & Arthropoda & Insecta & $\begin{array}{l}\text { Diptera } \\
\text { Coleoptera } \\
\text { Lepidoptera } \\
\text { Collembola } \\
\text { unidentified }\end{array}$ & $\begin{array}{l}17 \text { species or morphospecies; } 4 \text { families } \\
1 \text { family } \\
2 \text { broad groups - Lepidoptera and Microlepidoptera } \\
2 \text { morphospecies } \\
4 \text { morphospecies }\end{array}$ \\
\hline
\end{tabular}


to a coarser taxonomic level. Oligochaetes, nematodes and nemerteans were relatively abundant in some samples, but were not identified further Other crustaceans and other phyla were rare and not generally identified further than order, class or phylum (Table 1). For the purposes of this study, it was not necessary that all specimens be identified to species, nor that each phylum be identified to the same taxonomic resolution.

The 93 taxa were then divided into 9 groups according to their phylogeny and ecology (Table 1). These were cost-effective to sort and could be consistently identified with limited training. Molluscs were separated into 2 groups, gastropods and bivalves (Groups $A$ and $B$ ), because bivalves colonise new patches of habitat as larvae, whereas gastropods can move among patches as adults. Oligochaetes, nematodes and polychaetes dominate at different stages in newly created wetlands (Levin et al. 1996, Simenstad \& Thom 1996). Therefore, polychaetes were grouped into a single group (Group C) and oligochaetes, nematodes and nemerteans were grouped together in another major group (Group D). Amphipods (Group E) and isopods (Group F) were kept separate from all other crustaceans, which were relatively sparse (Group G). Insect larvae were grouped together (Group I). Finally, all other taxa were placed into a single group (Group $H$ ). These were sparse and did not contribute in any significant manner to differences among samples.

Analysis of spatial patterns. Differences in the assemblages among sites within and among locations were quantitatively compared using ANOSIM and the patterns then illustrated in nMDS plots (Clarke 1993) using the 2 levels of taxonomic resolution at each time of sampling.

At each level of taxonomic resolution, average BrayCurtis measures of dissimilarity from all pairs of quadrats within each site were obtained for each time of sampling ( $n=6$ pair-wise comparisons per measure), thus providing 16 measures of spatial. variability within sites (an average measure from all quadrats in each of 8 sites at each time). Average Bray-Curtis measures of dissimilarity were similarly calculated from the values for all pairs of quadrats compared between sites in the same location (calculated from $n=16$ pair-wise comparisons for each pair of sites), thus providing 8 of these measures at each level of taxonomic resolution (1 from each of the 4 locations from each time of sampling). These provided quantitative measures of variability of the assemblages at scales of metres (among quadrats) and tens of metres (between sites) for each location.

To examine spatial variability at the scale of locations (hundreds of metres), the 4 quadrats in each site at each time were randomly divided into 2 pairs. The quadrats in each of these pairs were compared with a pair of quadrats from each of the 2 sites in another location. For example, the 2 pairs of quadrats in Site 1, Location 1 were compared with a pair of quadrats in Site 1, Location 2 and a pair of quadrats in Site 2, Location 2. For each of these comparisons ( $n=4$ pair-wise comparisons for each average), the average Bray-Curtis measure of dissimilarity was calculated. The other pair of quadrats in each site in Location 2 was then available for other comparisons. Similarly, the quadrats in Site 2, Location 1 were compared with quadrats in Sites 1 and 2, Location 3 , etc. These gave 8 measures of average dissimilarity among sites in different locations at each time of sampling. They include variability at the scale of metres (quadrats), tens of metres (between sites) and hundreds of metres (among locations). These values were calculated for each level of taxonomic resolution.

The average Bray-Curtis measures obtained using different levels of taxonomic resolution were compared using Pearson's correlation co-efficient at each spatial scale. The within-site measures (smallest spatial scale) test the hypothesis that sites would retain their relative measures of variability (patchiness of the assemblages at the scale of metres) when examined at a coarser taxonomic resolution. Comparisons between sites within locations and among locations test the hypothesis that sites that are more similar at one level of taxonomic resolution remain more similar when a coarser level of taxonomic resolution is used. Such comparisons were made between sites and locations. Significant positive correlation would show that coarser taxonomic resolution shows spatial patterns in the assemblages at each spatial scale similar to those shown with finer taxonomic resolution. These data are not independent because the same samples were used for each resolution. Significance of these correlations (at $p=0.05$ ) was obtained by randomizing one set of each pair of values 1000 times to provide a null distribution, recalculating $r$ each time. This is justified if the points on the graph are independent of each other.

The same sites were sampled, with an independent set of replicates at each time, so samples were independent. To test further the hypothesis that data were independent from time to time (and, thus, to justify the use of both sets of data in the analyses), the average Bray-Curtis measures of dissimilarity within each site ( $\mathrm{n}=8$ sites) and between sites among the different locations ( $\mathrm{n}=24$ such comparisons) were compared between March and June using Spearman rank correlation co-efficients and the finest level of taxonomic resolution. Measures of variability between sites within locations could not be tested because of the small number of data $(n=4)$. The correlations were repeated for the untransformed and transformed data. All correlations were non-significant (at $p>0.05$ ), thus justifying combining the data from March and June in the analyses. 
These analyses were repeated after the data had been transformed to the fourth root. This has been recommended as an appropriate transform for multivariate analyses such as ANOSIM (Clarke 1993).

\section{RESULTS}

\section{Differences in the assemblages between sites and among locations}

At each time of sampling, similar patterns of variability in the assemblage were shown at each level of taxonomic resolution (illustrated for June 1995 with transformed data in Fig. 1). Relative differences among assemblages were retained at all spatial scales. For example, the quadrats in each site in Location 4 grouped more closely to each other than did those in each site in Location 3 and this was true at each taxonomic resolution. At each resolution, the 2 sites in Locations 1 to 3 were significantly different, whereas those in Location 4 were similar (ANOSIM, $p<0.05$; Clarke 1993). Finally, the locations grouped into 3 groups which separated from each other: Locations 1 and 2, Location 3 and Location 4 (Fig, 1). These patterns were retained when the taxa were grouped into 9 groups. Therefore, fine and coarse taxonomic resolution identified similar patterns in the assemblages at each spatial scale.

\section{Differences in the assemblages within and among sites}

At each scale (among quadrats within sites, between sites within locations, among locations), the average Bray-Curtis measures of dissimilarity were significantly correlated between the 2 levels of taxonomic resolution (Fig. 2). Therefore, at the smallest scale, sites that showed more variability (i.e. greater dissimilarity) from quadrat to quadrat at the finest taxonomic resolution were also more variable when the taxa were grouped. Similarly, at the scales of tens and hundreds of metres, relative differences between sites were retained, i.e. sites that were more dissimilar using one taxonomic resolution were also more dissimilar using the other level of taxonomic resolution.


Fig. 1. nMDS plots of benthic assemblages in each of 2 sites (filled and empty symbols) in each of 4 locations when the organisms were (a) sorted to 93 taxa and (b) combined into 9 broad groups. Each point represents a sample. Data transformed to $X^{025}$. Dotted lines indicate similar groupings

$(\boldsymbol{\Delta}, \Delta)$ Location $1 ;(\bullet, 0)$ Location $2 ;(\boldsymbol{\square}, \square)$ Location $3 ;(\bullet, \diamond)$ Location 4
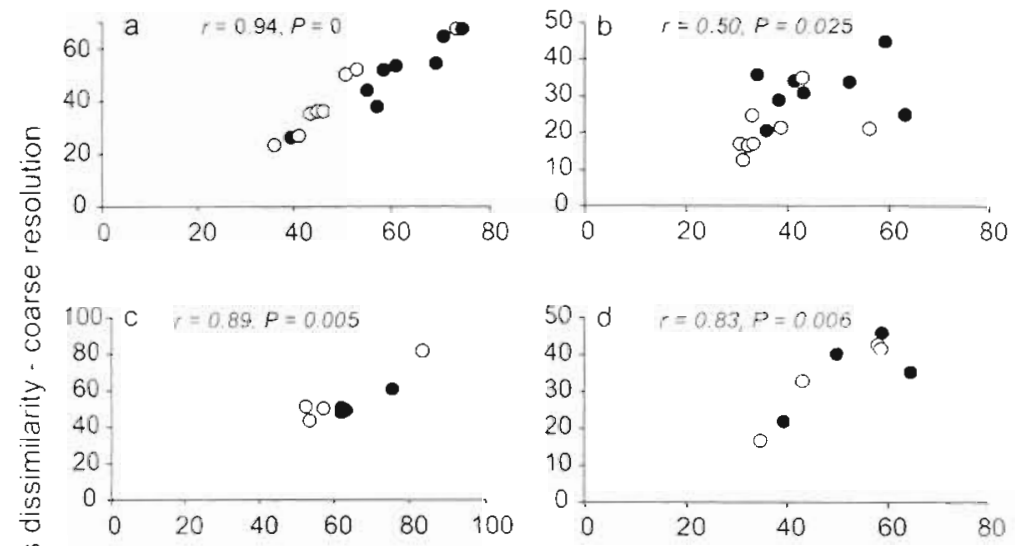

Fig. 2. Relationships between Bray-Curtis measures of dissimilarity calculated from 2 levels of taxonomic resolution: $(a, b)$ among quadrats within sites (each point represents a site), (c,d) between sites $40 \mathrm{~m}$ apart and $(\epsilon, f)$ among sites hundreds of metres apart (each point represents the difference between 2 sites). ( $a, c, e)$ Untransformed data; $(b, d, f)$ data transformed to fourth root. (•) March 1995; (O) June 1995

At all scales, the Bray-Curtis measures were smaller when taxa were grouped, indicating that the samples were more similar. There are many differences in the numbers of individuals in each of several taxa from one sample to another. If the taxa are combined (to give broader groupings), such differences will tend to cancel out. This must lead to smaller measures of dis- 
similarity. Nevertheless, relative differences among samples were retained.

Untransformed data were strongly correlated at all spatial scales (Fig. 2a, $c$, e). At all scales, transformed data (Fig. 2b, d, f) were less well correlated than untransformed data (Fig. 2a, c, e), particularly at the smallest spatial scale. For data that were transformed, in many sites, average variability among quadrats was altered by reducing the taxa to 9 groups, thus changing the relative measures of within-site dissimilarity (compare Fig. 2a with b). This tendency was not as strong when comparing differences between sites tens (Fig. 2d) or hundreds of metres apart (Fig. 2f).

\section{DISCUSSION}

The benthic assemblages were extremely variable at a range of spatial scales: from quadrat to quadrat (metres apart), site to site (tens of metres apart) and among locations (hundreds of metres apart) (Chapman \& Underwood unpubl. reports). Patchiness of organisms has been found in other soft-sediment habitats when assemblages have been sampled at a hierarchy of spatial scales (Morrisey et al. 1992, 1993, Thrush et al. 1994). Despite this variability, patterns of variation and relative differences among sites tens and hundreds of metres apart were similar at the 2 levels of taxonomic resolution. Thus, grouping 93 taxa (varying from species to phyla) into 9 broad categories preserved quantitative patterns of spatial variability of these assemblages and could identify significant differences among sites and locations. Each taxonomic resolution consistently identified differences between unflushed and waterlogged patches of forest (Locations 1 and 2), unflushed and drained patches of forest (Location 3) and tidally flushed patches of forest (Location 4), in addition to showing significant differences between sites in some locations.

Similar effects of reducing taxonomic resolution have been found in forests (Oliver \& Beattie 1996) and subtidal soft-sediment meiofauna (Somerfield \& Clarke 1995) and macrofauna (Gray et al. 1988, Warwick 1988, James et al. 1995). Generally, taxonomic resolution has varied on phylogenetic scales (e.g. species to genera), although some authors have examined ecological attributes (Somerfield \& Clarke 1995). In this study, taxa were grouped according to taxonomy (e.g. molluscs were separated from crustaceans), potential to colonize new patches of habitat (bivalves were separated from gastropods because the latter can move among patches of habitat as adults), relative diversity and abundances (amphipods and isopods were separated from other crustaceans) and documented patterns of diversity in wetlands of different ages (polychaetes were separated from oligochaetes, nematodes and nemerteans) (Levin et al. 1996, Simenstad \& Thom 1996). These criteria gave groups that identified and measured significant differences among patches of habitat at scales of tens and hundreds of metres. These results support previous studies demonstrating redundancy of information in large sets of species for identifying significant differences among assemblages (Gray \& Pearson 1982, Gray et al. 1988), where similar patterns of differences were obtained using a mid-ranking set of species, as were shown by random groups of species.

In this study, different levels of taxonomic resolution give the same pattern because the 2 measures are strongly correlated. Sites which have larger internal variability (larger measures of dissimilarity among quadrats) using one level of taxonomic resolution were also more variable using a different level of taxonomic resolution. Sites that were more similar to each other when 93 taxa were used remained more similar to each other when the taxa were grouped into 9 major groups. Therefore, these groups retained patterns of differences between sites.

Transforming the data to the fourth root retained patterns of differences between sites, but altered patterns of variability within sites (although the data were still significantly correlated). This transformation reduces the contribution to measures of dissimilarity of abundant species relative to rare ones. These results suggest that differences among quadrats within sites are mostly determined by relative abundances of individual taxa within the major groups. Altering the relative importance of these taxa by transformation causes loss of ability to detect patterns because the relative importance of individual taxa no longer correlates well with the importance of the major groups. Therefore, abundances of individual taxa are more important in determining differences among quadrats within sites. Sites that show most variability between quadrats when all taxa were used were not the most variable sites when the taxa were grouped.

Differences between sites or among locations, which are usually the comparisons of interest in most studies, were retained when the data were transformed, suggesting that differences in assemblages at these larger spatial scales are largely due to differences in the major groups, i.e. changes at the level of orders or phyla. Olsgard et al. (1997) simultaneously examined effects of altering taxonomic resolution and transforming the data on results of ANOSIM tests on soft-sediment macrofauna along a gradient of pollution. They, too, found that transformation had stronger effects on the measured patterns than did changing resolution. with decreased ability to identify pattern for analyses of strongly transformed data at the coarsest taxonomic 
resolution. Changing taxonomic resolution had very little effect on untransformed or weakly transformed $\left(X^{05}\right)$ data. From a study of the literature, there appears to be an automatic tendency to transform data to $X^{025}$ before proceeding with ANOSIM or nMDS plots. Both the transformations and levels of taxonomic resolution used can strongly influence the significance of any results obtained (Olsgard et al. 1997) and should be carefully considered in the light of the hypotheses being tested before each is selected

Use of coarser taxonomic resolution has advantages in benthic sampling programmes where most resources are spent sorting samples in the laboratory, it being relatively quick and easy to collect samples in the field. Sampling could be made more cost-effective if the time necessary to sort samples were reduced. In this study, 3 independent estimates of the proportion of time needed to sort a sample to 9 major groups instead of 93 different taxa were (1) less than $40 \%$, (2) between 30 and $50 \%$ and (3) less than $50 \%$. Therefore, 2 to $2 \frac{1}{2}$ times as many samples could be sorted to major groups in the same time that it takes to sort a given number of samples to the finest resolution possible. In addition, there is no expertise within Australia for identification of many groups to species level (e.g. Dipteran larvae, which were the most numerous insect larvae in these samples: R. Russell, University of Sydney, pers. comm.), which means that, even at the best taxonomic resolution possible, resolution is necessarily arbitrarily inconsistent from phylum to phylum (see also Grall \& Grémarec 1997). This is undoubtedly a widespread problem.

Finally, there has been little work on spatial and temporal variability of benthic fauna in intertidal mangrove forests at a hierarchy of spatial and temporal scales, but the present and other unpublished data show considerable small- and large-scale variability in the assemblages. Replicate quadrats varied inconsistently from site to site. Some patches of forest showed significant differences in assemblages between sites $40 \mathrm{~m}$ apart, others did not. Assemblages changed significantly over periods of 3 mo and these changes interacted with spatial patterns and varied from site to site (Chapman \& Underwood unpubl. reports). Such unpredictable variability has also been reported for subtidal sandy habitats (Morrisey et al. 1992, 1993) and intertidal mudflats (Thrush et al. 1994). James et al. (1995) examined changes in assemblages in soft-sediment macrofauna at the scales of locations (tens of kms apart), sites within locations ( 2 to $3 \mathrm{~km}$ apart) and different depths. They found that changing taxonomic resolution retained patterns among depths and locations. Their paper, however, did not allow comparison at the smallest spatial scale, within sites. All of the spatial scales in the present study were smaller than theirs.
In these habitats, many samples, at a range of different scales, are necessary to provide adequate representation of these assemblages and to quantify differences among places and changes through time. Sampling at only one scale in time or space cannot provide this information. This study shows that patterns can be consistently identified using different levels of taxonomic resolution. It is suggested that, when resources are limited, for consistent patterns to be measured, it is more important to collect enough replicates at a range of spatial and/or temporal scales so that the assemblages are well represented than to sort the taxa to a fine taxonomic resolution. It is essential that these recommendations not be seen simply as a short-cut to save money without re-allocation of the released resources to where they are needed. A pilot study could determine the level of taxonomic resolution and sampling design needed and, therefore, would allow the best use of limited resources in the study (Underwood 1997).

Acknowledgements. Thanks to P. Barnes, R. Cawley, J. Cunningham, P. Gibson, J. Harris, V. Mathews and S. McCune for practical assistance; for help with identification, thanks to $\mathrm{M}$. Geary and R. Russell (insect larvae), I. Loch (molluscs), J. Stark (polychaetes) and M. Schreider (amphipods). This study was funded by the Olympic Co-ordination Authority and funds from the Institute of Marine Ecology. M. J. Anderson, A. J. Underwood and 3 anonymous referees made helpful comments on a previous draft of this manuscript.

\section{LITERATURE CITED}

Bustamante RH, Branch GM (1996) Large scale patterns and trophic structure of southern African rocky shores: the roles of geographic variation and wave exposure. J Biogeogr 23:339-351

Chapman MG, Underwood AJ, Skilleter GA (1995) Variability at different spatial scales between a subtidal assemblage exposed to the discharge of sewage and two control assemblages. J Exp Mar Biol Ecol 189:103-122

Clarke KR (1993) Non-parametric multivariate analyses of changes in community structure. Aust J Ecol 18:117-143

Clarke KR, Green RH (1988) Statistical design and analysis for a 'biological effects' study. Mar Ecol Prog Ser 46: $213-226$

Grall J, Glémarec M (1997) Using biotic indices to estimate macrobenthic community perturbations in the Bay of Brest. Estuar Coast Shelf Sci 44(Suppl A):43-53

Gray JS, Aschan M, Carr MR, Clarke KR, Pearson TH, Rosenberg R, Warwick RM (1988) Analysis of community attributes of the benthic macrofauna of the Frierfjord/Langesundfjord and in a mesocosm experiment. Mar Ecol Prog Ser 46:151-165

Gray JS, Clarke KR, Warwick RM, Hobbs G (1990) Detection of intitial effects of pollution on marine benthos: an example from the Ekofisk and Eldfisk oilfields, North Sea. Mar Ecol Prog Ser 66:285-299

Gray JS, Pearson TH (1982) Objective selection of sensitive species indicative of pollution-induced change in benthic communities. I. Comparative methodology. Mar Ecol Prog Ser 9:111-119 
James RJ, Lincoln-Smith MP, Fairweather PG (1995) Sieve mesh size and taxonomic resolution needed to describe natural spatial variation of marine macrofauna. Mar Ecol Prog Ser 118:187-198

Levin LA, Talley D, Thayer G (1996) Succession of macrobenthos in a created salt marsh. Mar Ecol Prog Ser 141:67-82

Morrisey DJ, Howitt L, Underwood AJ, Stark JS (1992) Spatial variation in soft-sediment benthos. Mar Ecol Prog Ser 81. $197-204$

Morrisey DJ, Underwood AJ, Howitt L (1993) Scales of spatial patchiness in the distribution of marine soft sediment faunas. In: Battershill CN, Schiel DR, Jones GP. Creese RG, MacDiarmid $A B$ (eds) Proc 2nd Int Temperate Reef Symp. NIWA Marine, Wellington, p 107-113

Oliver I, Beattie AJ (1996) Designing a cost-effective invertebrate survey: a test of methods for rapid assessment of biodiversity. Ecol Appl 6:594-607

Olsgard F, Somerfield PJ, Carr MR (1997) Relationships between taxonomic resolution and data transformations in analyses of a macrobenthic community along an established pollution gradient. Mar Ecol Prog Ser 149: $173-181$

Simenstad CA, Thom RM (1996) Functional equivalency trajectories of the restored Gog-Le-Hi-Te estuarine wetland. Ecol Appl 6:38-56

Editorial responsibility: Tony Underwood (Contributing

Editor), Sydney, Australia
Somerfield PJ, Clarke KR (1995) Taxonomic levels, in marıne community studies, revisited. Mar Ecol Prog Ser 127 $113-119$

Thrush Si: Pridmore RD, Hewitt JE (1994) Impacts on softsediment macrofauna: the effects of spatial variation on temporal trends. Ecol Appl 4:31-41

Underwood AJ (1994) On beyond BACl: sampling designs that might reliably detect environmental disturbances Ecol Appl 4:3-15

Underwood AJ (1997) Experiments in ecology: their logical design and interpretation using analysis of variance. Cambridge University Press, Cambridge

Underwood AJ, Chapman MG (1996) Scales of spatial patterns of distribution of intertidal snails. Oecologia 107 $212-224$

Underwood A.J, Chapman MG (1998) Spatial analysis of intertidal assemblages on sheltered rocky shores. Aust $J$ Ecol (in press)

Warwick RM (1988) Analysis of community attributes of the macrobenthos of Frierfjord/Langesundfjord at taxonomic levels higher than species. Mar Ecol Prog Ser 46:167-170

Warwick RM, Clarke KR, Gee JM (1990) The effect of disturbance by soldier crabs, Mictyris platycheles $\mathrm{H}$. Milne Edwards, on meiobenthic community structure. J Exp Mar Biol Ecol 135:19-33

Submitted: September 8, 1997; Accepted: November 28, 1997 Proofs received from author(s): February 5, 1998 